\title{
The Universal Artificial Intelligence Efforts to Face Coronavirus COVID-
}

\section{9}

\author{
Maged Farouk \\ Onaizah Colleges, Saudi Arabia, and Workers University, Egypt, Magedfarouk5@gmail.com
}

\begin{abstract}
Artificial intelligence (AI) has already changed the world and has made an effective impact in a range of fields including industry, criminal law, health, national security, transport, nanotechnology, intelligent cities as well as issues such as algorithms and access to the data. This paper shows how these technologies are a great asset to humans and are programmed to reduce human effort as much as possible. They tend to possess the capability to work in an automated fashion. Therefore, manual intervention is the last thing that could be asked for or seen while operating parts associated with this technology. As well as the paper shows the different universal efforts of AI techniques to face the pandemic of COVID-19.
\end{abstract}

Keywords: Artificial Intelligence Techniques, COVID19.

\section{INTRODUCTION}

Although the concept of Artificial Intelligence (AI) has long existed, many researchers believe that it is time for AI to be a reality. Computer science refers to AI research as a "Smart Agents" study: any system which sees and acts in a way that maximizes its opportunities to meet its goals [1]. In 1950, Claude Shannon proposed the concept of computers playing chess. In the early 1960s, AI began. Marvin Minsky believed "the problem of AI simulation is going to be solved within a decade". The first AI applications were introduced during that period. In [2] discussed various ideas on humanoid robots were put into practice in antiquity Greek times. Daedelus, who controlled wind mythology and tried to create artificial people, is an example. Modern AI has begun to be used in history to explain the philosopher's model of human thinking. However, Using AI not only engaged with engineering, information technology, finance, and accounting, 
medicinal, marketing, agriculture, human resource management, law, education, sciences of space, customer services but also contribute greatly to the performance of tasks effectively [3]. It is important to facilitate our lives. This paper shows how these technologies are a great asset for humans and are designed as much as possible to reduce human effort. They tend to be able to work in an automated way. The last thing that could be requested or seen in the operating parts associated with this technology is therefore manual intervention.

\section{WHAT IS AI?}

Much research defined AI in varies ways. The ability of a system to interpret external data accurately, learn about it and use it to achieve specific objectives and tasks through various changes is one of the most common meanings of AI's concepts [1]. Another definition, AI is an analytical computer assisted course that seeks to shape automated systems which could be referred to as smart systems [4]. Moreover, [4] defined AI as the machine-shaped human intelligence. AI is an attempt to create smart entities which can equal or surpass human intelligence and rationality [5]. "The science of making machinery does what, if done by men, would necessitate intelligence [6]. John McCarthy say that logical reasoning is a "standard" more influential than human capacity to quantify intelligence [7]. This approach to AI uses mathematical logic approaches to officialize the complex tasks artificial intelligence machines perform.

\section{The Characteristics OF AI}

According to [8], as shown in Fig. 1, the most important characteristics for AI are:

- Deep Learning: A machinery that teaches computers to learn by example what naturally happens to humans. There are many areas of AI technology, such as autonomous vehicles, computer vision, automatic text generation, and the like, where deep learning is increasing in scope and use.

- Facial Recognition: Facial recognition enabled individual faces to be recognized by means of biometric mapping. The progress made in surveillance technologies has been path breaking. The knowledge is compared to a database of known faces to find a match.

- Automate Simple and Repetitive Tasks: Without breaking a sweat, AI could do the same work repeatedly. For example, Siri, an Apple Inc. voice assistant. In a single day, it can 
handle so many orders. Automation would not only increase efficiencies but would also lead to lower overhead costs and a safer working environment in some circumstances.

- Data Ingestion: Data ingestion means that knowledge is transported from different sources to a data storage medium where a company frequently accesses, uses, and analyzes it. AI analyzes a large number of these data with the help of neural networks and contributes to a logical conclusion from it.

- Chatbots: Chatbots are software that provides a window with either audio or textual input to solve customer problems. Before bots, only certain commands were used to respond. It did not know what you meant if you said the wrong thing. Now when you are talking to the chatbot you do not have to be ridiculously specific. It knows not just commands but language. The chatbots not only provide services focused on problems faced by customers, but also provide users with product suggestions. That is all due to AI alone.

- Quantum Computing: The field focuses on the creation of quantum algorithms for computer-based work within AI, such as machine learning. It is an interdisciplinary field.

- Cloud Computing: Data storage would have been a serious problem if such a large number of information had been channeled every day. Capabilities AI's work in the cloud-based enterprises to make organizations more efficient, strategic, and insight-oriented.

\section{AI TEChNIQUES}

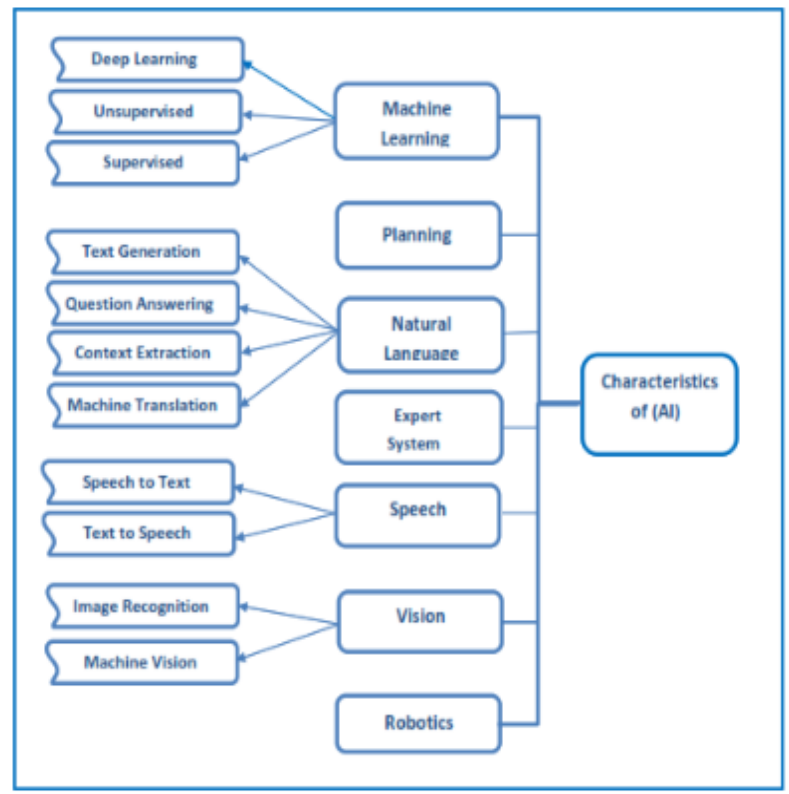

Fig. 1. Characteristics of AI 
The positive impact of AI reaches almost every dimension of human life. AI was applied for several models, forecasts, and decision support and control systems in such diverse fields as engineering, economics, linguistics, law, manufacturing, and medicine [8-9]. The following are examples for how AI techniques are taking part in different fields of life:

\section{A. Applying AI Techniques in Finance Filed}

The financial services industry includes AI for massive processing of data, trading, online communication with clients and performing a variety of other essential functions. In [10] carried out a study to search for AI's effect on the real world, on finance, which has been of significant benefit to many financial sectors from the implementation of AI applications. He concluded that AI technology would increase efficiencies, lower costs, enhance efficiency, boost customer satisfaction levels, and encourage financial inclusion in the provision of financial services. There are many researches which presented the benefits of using AI in finance [11-14].

\section{B. Applying AI Techniques in Human Resource Filed}

In [45] explained that although the effectiveness of using AI in Human Resource (HR) practice, most organizations continue to be lagging in integrating AI with HR practices due to their integration costs or are afraid that some business processes may be handled by a non-human entity. Moreover, other researchers presented how AI is effective tool in HR [15-16].

\section{Applying AI Techniques in Civil Engineering Filed}

In the field of adaptive civil engineering systems, [2] have made progress. In an active tensegrity system control setting, self-diagnosis, multi-target type management and enhancement learning processes have been introduced. It is Specifically suitable for modeling complex systems with known input-output data sets among AI computer technologies. The modeling of cement-based materials can be efficient, non-linear, complex, and unambiguous using single, dual, or multiple damage factors. Many other researchers made development in that field [16-19]. 


\section{Applying AI Techniques in Healthcare Filed}

AI is already used effectively in the field of health care, ranging from online appointments planning to online checks, follow-up appointments calls for reminders, diagnosis of the aid for diseases, assistance with procedures of surgery, radiation treatment and offering mental health therapy [20-21]. Japan has the leadership in using of AI technology in health care. It has already introduced AI robots helping geriatric people to workday by day, from taking morning pills to adjusting the $\mathrm{AC}$ temperature during bedtime. It is also useful in the diagnosis of Glaucoma [22]. In China, a primary method for early diagnosis of COVID-19 was AI-powered CT scanning of the lungs, reducing the time spent on diagnosing a case from 30 minutes to seconds. The branch that has been the most up-to-date and welcoming to the use of new technology in clinical imaging and storage is radiology. By identifying rapid negative tests in computed tomography, X-rays, magnetic resonance imaging, particularly in high volume settings, and in hospitals with less available human resources, AI could provide substantial support in radiology [20]. Currently, three South Korean medical institutions, Gachon University Gil Medical Center, Pusan National University Hospital and Konyang University Hospital, have introduced IBM's Watson for Oncology artificial intelligence system that can identify, evaluate and compare treatment options by understanding the medical record and applying its training to each individual patient [23].

\section{E. Applying AI Techniques in Marketing Filed}

In [24] showed that implementing AI is useful for future marketing strategy growth. AI is a tool for digital marketers to inspire them and tricks you to get the brand or an individual or group of people to learn it and make it high. It is fair to assume that AI is a secure investment that earns dividends [25]. To convert digital systems into all sectors that contribute to technological progress that will help in economic development, AI technology is a goal for Saudi Arabia during the current period of its [26] initiative to be one of the leading countries in Middle East in implementing and investing of AI applications for the sake of society and individuals [27]. 


\section{F. AI Techniques in Wastewater Treatment Field}

There are many studies covered the effective role of the importance of technological advancement such as AI techniques in the chemical analysis and wastewater treatment. [28] stated in their study the importance of AI technologies in treatment processes of the effluent discharge from hospitals that has an eminent quantity of chemical waste. [29] covered some aspects of the worldwide disposal and regulatory standard for hospital effluent discharge, its managements and treatment technologies that are widely implemented and perfectly suited. To treat $10 \mathrm{~m} 3 /$ day of hospital wastewater, a pilot scale CW system was used. The system was tested for 3 months to assess its efficiency in wastewater removal. With all removal efficiency 94\% (COD), MLSS (97\%), TSS (98\%), BOD5 (96\%), Phosphate (98\%), HSFCW coupled with a tube settler $(79 \%)$ [30].

\section{G. AI techniques in Nanotechnology Field}

[31] also discussed the fact that since the 1994 development of nanotechnology, developed countries have sought the use

of modern technologies in all fields, including water purification, in their study entitled "Water and Wastewater Treatment using nanotechnology. There were positive results compared to other water treatment techniques because of their high surface area (superface/volume ratio), metal containing nanoparticles, carbonaceous nanomaterials, zeolites and dendrimers and nanofibers. In their paper, [32] discussed a few recently used nanomaterials that are currently used in water treatment, with an emphasis on nano-based adsorbents and filtration membranes.

\section{SCOPE OF AI in The Middle EAST Beyond 2030}

The scope will almost certainly increase after 2030, when AI affects the economy and society. The complexity of AI would almost certainly grow both in the economy and in society. Therefore, to provide a springboard for the future it is necessary for the Middle East to be strategically positioned. The most significant gains, which are equivalent to $12.4 \%$ of GDP, are expected, in absolute terms. AI in Saudi Arabia is contributing over USD 135,2,2 billion to the economy by 2030 . The UAE is projected to have a significant effect in comparison with approximately $14 \%$ of GDP in 2030. As well as the expected annual contribution growth for Bahrain, Kuwait, Oman, and Qatar is 14\% of GDP [33]. 


\section{Contribution of AI to Gross Domestic Product (GDP) By 2030}

The International Data Corporation (IDC) analysis estimates that the Middle East and Africa (MEA), cognitive and AI system expenditure will grow from 37,5 million dollars in 2017 to over 100 million dollars in 2021, which is a $32 \%$ increase yearly [33].

\section{The Development of AI Techniques in The Developed Countries}

Innovative intelligent manufacturing strategies and policies have been formulated by developed countries, such as the United States and Germany, using AI, such as the Advanced Manufacturing Partnership Plan (2011) and the Industrial Internet (2012) in the United States and the Industry 4.0 Plan (2013) in Germany. The 'Industrial Internet' was adopted by the U.S., which can intelligently analyze intelligent equipment, employees, and data in an intelligent way to make smarter decisions possible. This achieved such a good result. Significant results have been achieved by CPS-based smart manufacturing technology in Germany, e.g., in Germany The Amberg plant is a smart plant model of the Siemens company. The real factory is run together with the virtual factory at Amberg, and the real factory data and production environments are reflected by the virtual factory through which individuals can manage and control the real factory. Almost $75 \%$ of the manufacturing operations have been automated. In robotics, autonomous vehicles, and quantum computing, Germany also has leadership [34]. Chinese scholars have built various types of AI models in China to predict the consumption of petroleum. The large amount of data in the financial market could be used for analysis by artificial intelligent algorithms [35]. According to an online survey of students conducted at Canadian medical schools, as well as in Canada, they expect to add AI to the curriculum as a complement to radiology [36].

\section{Universal AI EfForts to Face Coronavirus COVID-19}

Medical image processing, which has recently appeared in several coronavirus research studies, has been using AI techniques as a fundamental function for COVID-19 detection. [37] for other uses of the DL in medical image analysis. It is recognized from these studies that X-ray images and computed tomography (CT) scans are commonly used to automatically detect the infected case of COVID-19 as a DL model input. A deep convolutionary neural network (CNN) model was developed for the detection of COVID-19 cases in [38]. The proposed CNN model can 
achieve an accuracy of 93.3 percent by practicing 13,975 images of 13,870 patients on an opensource dataset [39-44] considered the use of ML and DL techniques for COVID-19 detection with chest CT scans. These works show high performance as they can achieve a high classification accuracy, e.g., 99.68\% in [45], an area under curve (AUC) score of 0.994 in [43], AUC of 0.996 in [45], and $82.9 \%$ accuracy (98.27\%) with $80.5 \%$ accuracy $(97.60 \%)$ and $84 \%$ sensitivity (98.93\%) in [43-44].

\section{A. Apple and Google Team Up to " Contact Trace" COVID-19}

Apple and Google have been creating mobile applications that tell users whether they are linked to someone who has recently been infected. The group plans to team up in a few months to deliver the product, which is built into billions of iPhones and Android devices worldwide. That would permit smartphones to log in to other devices they come near, enabling the socalled touch tracking of the disease, and these have succeeded in areas such as South Korea, where mass virus tests have been carried out [45].

\section{B. Speeding Up Drug Discovery and Development}

AI can enable new drugs and vaccines to be detected, develop, and measured faster than ever. For instance, Insilco Medicine, a portfolio company of Longevity Vision Fund, was able to use its AI techniques for successfully recognizing thousands of molecules in just four days for possible medications. Insilco Medicine then launched an open policy and published the updated results on its website to allow all researchers to download the data free of charge, ultimately contributing to the global fight against the epidemic [45].

\section{Reducing Fatality and Optimize Disease Management}

Applying AI techniques can help in controlling the epidemic and reduce deaths by reducing the burden on healthcare workers and by reminding patients of correct treatment procedures. Medical care staff members are at high risk of exposure and contraction to Covid-19. Until now, Covid-19 has infected thousands of Medical care staff members in China as well as many other countries. AI can help to alleviate the burden. For instance, China uses robots to provide faster diagnostic tests. Also, AI assists Hangzhou City Ambulances to speed up traffic. 
Moreover, AI can also help people to better understand what their reactions should be in case they affected with the virus. China has released an App that lets people verify whether a confirmed COVID-19 patient has taken a flight or a train. Moreover, it is using drones to ensure adequate measures are taken by the residents [45].

\section{Forecasting Epidemics}

Applying AI techniques can alert from an impending outbreak and give people ample time to plan for it. To evaluate information from a variety of sources and monitor over a hundred infectious diseases, BlueDot, a global AI software company, uses AI-powered algorithms, machine learning, and natural language processing. In the coming days, it is expected that AI could even use social media data to predict human actions and possible outbreaks [45].

\section{CONCLUSION}

Artificial intelligence is known for a long time now for its importance and its subsequent components. They are seen to make this world a better place as instruments and techniques.

These machines tend to speed up your processes and tasks with a guaranteed degree of accuracy, making them an important and useful tool.

These technologies and applications are not only related to our overall and everyday life, in addition to making the world an error free place with their simple and daily techniques.

It also affects and is important for other areas too.

\section{REFERENCES}

[1] Giri, A., et al., (2019) . Determining the impact of artificial intelligence on 'Developing Marketing Strategies' in Organized Retail Sector of West Bengal, India. International Journal of Engineering and Advanced Technology, 8(6): p. 3031-3036.

[2] Alhashmi, S.F.; Salloum, S.A.; and Mhamdi, C. (2019). Implementing artificial intelligence in the United Arab Emirates healthcare sector: an extended technology acceptance model. Int. J. Inf. Technol. Lang. Stud, 3(3): p. 27-42. 
[3] Matsa, P. and K. Gullamajji . (2019). To Study impact of artificial intelligence on human resource. International Research Journal of Engineering and Technology (IRJET), 6(8).

[4] Shahid, M. Z., \& Li, G. (2019). Impact of artificial intelligence in marketing: a perspective of marketing professionals of pakistan. Global Journal of Management And Business Research.

[5] Hassan, O.( 2020). Artificial intelligence, neom and Saudi Arabia's economic diversification from oil and gas. the political quarterly. 91(1): p. 222-227.

[6] Winston, P.H. ( 2016). Marvin L. Minsky (1927-2016). Nature. 530(7590): p. 282-282.

[7] McCarthy, J., \& Hayes, P. J. (1981). Some philosophical problems from the standpoint of artificial intelligence. In Readings in artificial intelligence (pp. 431-450). Morgan Kaufmann.

[8] Mar, W., \& Thaw, Y. M. K. K. (2019). An analysis of benefits and risks of artificial intelligence.

[9] Mellit, A. and S.A. Kalogirou. (2008). Artificial intelligence techniques for photovoltaic applications: A review. Progress in energy and combustion science, 34(5): p. 574-632.

[10] Kunwar, M., (2019). Artificial intelligence in finance: understanding how automation and machine learning is transforming the financial industry.

[11] Dunis, C., et al., (2016). Artificial intelligence in financial markets. Springer.

[12] Green, H.G. ;and Pearson,M.A. (1995). Artificial intelligence in financial markets. in Proceedings of ICNN'95-International Conference on Neural Networks.IEEE.

[13] Manta, O. (2020). Financing and fiscality in the context of artificial intelligence at the global level. European Journal of Marketing and Economics, 3(1), 31-47.

[14] Zain, N. R., Hassan, R., \& Ismail, A. (2020). Enhancing islamic banking and finance in southeast Asia through the application of artificial intelligence: an exploration of banking's best practices. in impact of financial technology (FinTech) on islamic finance and financial stability (pp. 36-53). IGI Global.

[15] Johansson, J; and Herranen,S. (2019). The application of artificial intelligence (AI) in human resource management: Current state of AI and its impact on the traditional recruitment process. 
[16] Rodney, H., Valaskova, K., \& Durana, P. (2019). The artificial intelligence recruitment process: How technological advancements have reshaped job application and selection practices. Psychosociological Issues in Human Resource Management, 7(1), 42-47.

[16] Bassuoni, M; and Nehdi.M. (2008). Neuro-fuzzy based prediction of the durability of selfconsolidating concrete to various sodium sulfate exposure regimes. Computers and Concrete, 5(6): p. 573-597.

[17] Das, S.K.; Samui, P.; and Sabat,A.K. (2011). Application of artificial intelligence to maximum dry density and unconfined compressive strength of cement stabilized soil. Geotechnical and Geological Engineering, 29(3): p. 329-342.

[18] Kremen, P; and Z. Kouba. (2011). Ontology-Driven Information System Design. IEEE

[19] Prasad, B. R., Eskandari, H., \& Reddy, B. V. (2009). Prediction of compressive strength of SCC and HPC with high volume fly ash using ANN. Construction and Building Materials, 23(1), 117-128.

[20] Amisha, M.P.; Pathania,M.; and Rathaur, V.K. (2019). Overview of artificial intelligence in medicine. J Family Med Prim Care 2019;8:2328-31.

[21] Barstugan, M.; Ozkaya, U.; and Ozturk, S.(2020). Coronavirus (covid-19) classification using ct images by machine learning methods . arXiv preprint arXiv:2003.09424. Retrieved from:http://arxiv.org/abs/2003.09424.

[22] Bhattacharya, S.,et al., (2019). Artificial intelligence enabled healthcare: A hype, hope or harm. Journal of Family Medicine and Primary Care, 8(11): p. 3461.

[23] Chung, J.; and Zink, A. (2020). Hey Watson, can I sue you for malpractice? examining the liability of artificial intelligence in medicine. Retrieved 19 February 2020, from https://papers.ssrn.com/sol3/papers.cfm? .

[24] Giri, A., et al., (2019) . Determining the impact of artificial intelligence on 'developing marketing strategies' in organized retail sector of west Bengal, India. International Journal of Engineering and Advanced Technology, 8(6): p. 3031-3036.

[25] Murgai, A. (2018). Transforming digital marketing with artificial intelligence. International Journal of Latest Technology in Engineering, Management \& Applied Science, 7(4), 259-262

[26] Vision 2030. (2017). Vison 2030 Kingdom of Saudi Arabia, National Transformation Programme. Available from: 
https://www.vision2030.gov.sa/sites/default/files/report/Saudi_Vision2030_AR_2017.pd f.

[27] Ashehri, R. (2019). Governance of artificial intellegence in KSA (Neom as model). International Journal of Advanced Studies, 9(1), 64-81.

[28] Khan, N. A., et al. (2019) "Recent trends in disposal and treatment technologies of emerging-pollutants- a critical review," TrAC trends Anal. Chem., vol. 122, p. 115744.

[29] Khan, N.A, et al. (2019), "Smart ways of hospital wastewater management, regulatory standards and conventional treatment techniques", Smart and Sustainable Built Environment, Vol. ahead-of-print No. ahead-of-print. https://doi.org/10.1108/SASBE-062019-0079

[30] Khan, N. A., et al. (2020). Horizontal sub surface flow constructed wetlands coupled with tubesettler for hospital wastewater treatment. Journal of Environmental Management, 267, 110627.

[31] Khan, N. A.; Khan, K. A.; and Islam, M. (2012). Water and wastewater treatment using nano-technology. In Chemistry of Phytopotentials: Health, Energy and Environmental Perspectives (pp. 315-318). Springer, Berlin, Heidelberg.

[32] Khan, N. A., et al.(2019). Field hospital wastewater treatment scenario. Ecological Questions, 30(3), 57-69.

[33] PricewaterhouseCoopers (PwC).(2019). The potential impact of AI in the Middle East. Available from: https://www.pwc.com/m1/en/publications/potential-impact-artificialintelligence-middle-east.html

[34] Li, B., et al. (2017). Applications of artificial intelligence in intelligent manufacturing: a review. Frontiers of Information Technology \& Electronic Engineering, 18(1), 8696. doi:10.1631/fitee. 1601885 .

[35] Lu, Y. (2019). Artificial intelligence: a survey on evolution, models, applications and future trends. Journal of Management Analytics, 129. doi:10.1080/23270012.2019.1570365

[36] Gong, B., et al. (2018). Influence of artificial intelligence on Canadian medical students' preference for radiology specialty: A national survey study. Academic Radiology. doi:10.1016/j.acra.2018.10.007.

[37] Shen, D., Wu, G., \& Suk, H. I. (2017). Deep learning in medical image analysis. Annual review of biomedical engineering, 19, 221-248. 
[38] Statista.(2019). In-depth: artificial intelligence. statista digital market outlook' Available from: https://people.stfx.ca/x2011/x2011aqi/School/20182019/Winter/BSAD\%20471\%20-\%20Strat/Case/AI\%20statista.pdf

[39] Barstugan, M.; Ozkaya, U.; and Ozturk, S.(2020). Coronavirus (covid-19) classification using ct images by machine learning methods . arXiv preprint arXiv:2003.09424. Retrieved from:http://arxiv.org/abs/2003.09424.

[40] Dai, W.C, et al., (2020).CT imaging and differential diagnosis of COVID-19.Canadian Association of Radiologists Journal. 71(2): p. 195-200. Retrieved from : http://arxiv.org/abs/2004.03698.

[41] Gozes, O., et al.,( 2020). Coronavirus detection and analysis on chest CT with deep learning. arXiv preprint arXiv:2004.02640. Retrieved from : http://arxiv.org/abs/2004.02640.

[42] Gozes, O., et al.,( 2020). Rapid AI development cycle for the coronavirus (covid-19) pandemic: Initial results for automated detection \& patient monitoring using deep learning CT image analysis. arXiv preprint arXiv:2003.05037. Retrieved from: http://arxiv.org/abs/2003.05037.

[43] Ozkaya, U., S. Ozturk, and M, Barstugan. (2020). Coronavirus (COVID-19) Classification using deep features fusion and ranking technique.arXiv preprint arXiv:2004.03698. [online] Available: http://arxiv.org/abs/2004.03698.

[44] Wang, S., et al.,( 2020). A deep learning algorithm using CT images to screen for Corona Virus Disease (COVID-19). MedRxiv. [online] Available:https://www.medrxiv.org/content/10.1101/2020.02.14.20023028v5.

[45] Wu, J.( 2020). How Artificial Intelligence Can Help Fight Coronavirus. Availablefrom:https://www.forbes.com/sites/cognitiveworld/2020/03/19/how-artificialintelligence-can-help-fight coronavirus/\#56c2c3844d3a.

[46]. Aziz, N., \& Aftab, S. (2021). Data Mining Framework for Nutrition Ranking: Methodology: SPSS Modeller. International Journal of Technology, Innovation and Management (IJTIM), 1(1), 85-95.

[47]. Radwan, N., \& Farouk, M. (2021). The Growth of Internet of Things (IoT) In The Management of Healthcare Issues and Healthcare Policy Development. International Journal of Technology, Innovation and Management (IJTIM), 1(1), 69-84. 
[48]. Cruz, A. (2021). Convergence between Blockchain and the Internet of Things. International Journal of Technology, Innovation and Management (IJTIM), 1(1), 34-53.

[49]. Lee, C., \& Ahmed, G. (2021). Improving IoT Privacy, Data Protection and Security Concerns. International Journal of Technology, Innovation and Management (IJTIM), 1(1), $18-33$.

[50]. Alzoubi, A. (2021) The impact of Process Quality and Quality Control on Organizational Competitiveness at 5-star hotels in Dubai. International Journal of Technology, Innovation and Management (IJTIM). 1(1), 54-68

[51]. Al Ali, A. (2021). The Impact of Information Sharing and Quality Assurance on Customer Service at UAE Banking Sector. International Journal of Technology, Innovation and Management (IJTIM), 1(1), 01-17.

[52]. Kashif, A. A., Bakhtawar, B., Akhtar, A., Akhtar, S., Aziz, N., \& Javeid, M. S. (2021). Treatment Response Prediction in Hepatitis C Patients using Machine Learning Techniques. International Journal of Technology, Innovation and Management (IJTIM), 1(2), 79-89.

[53]. Akhtar, A., Akhtar, S., Bakhtawar, B., Kashif, A. A., Aziz, N., \& Javeid, M. S. (2021). COVID-19 Detection from CBC using Machine Learning Techniques. International Journal of Technology, Innovation and Management (IJTIM), 1(2), 65-78.

[54]. Eli, T. (2021). Students Perspectives on the Use of Innovative and Interactive Teaching Methods at the University of Nouakchott Al Aasriya, Mauritania: English Department as a Case Study. International Journal of Technology, Innovation and Management (IJTIM), 1(2), 90-104.

[55]. Alsharari, N. (2021). Integrating Blockchain Technology with Internet of things to Efficiency. International Journal of Technology, Innovation and Management (IJTIM), 1(2), 01-13.

[56]. Mehmood, T. (2021). Does Information Technology Competencies and Fleet Management Practices lead to Effective Service Delivery? Empirical Evidence from ECommerce Industry. International Journal of Technology, Innovation and Management (IJTIM), 1(2), 14-41.

[57]. Miller, D. (2021). The Best Practice of Teach Computer Science Students to Use Paper Prototyping. International Journal of Technology, Innovation and Management (IJTIM), 1(2), 42-63. S. Y. 
[58]. Siddiqui, A. Haider, T. M. Ghazal, M. A. Khan, I. Naseer, S. Abbas, M. Rahman, J. A. Khan, M. Ahmad, M. K. Hasan, A. M. A, and K. Ateeq, "IOMT cloud-based intelligent prediction of breast cancer stages empowered with Deep Learning," IEEE Access, vol. 9, pp. 146478-146491, Oct. 2021.

[59]. S. Abbas, Y. Alhwaiti, A. Fatima, M. A. Khan, M. Adnan Khan, T. M. Ghazal, A. Kanwal, M. Ahmad, and N. Sabri Elmitwally, "Convolutional neural network based intelligent handwritten document recognition," Computers, Materials \& Continua, vol. 70, no. 3, pp. 4563-4581, Oct. 2021.

[60]. T. M. Ghazal, S. Abbas, S. Munir, M. A. Khan, M. Ahmad, G. F. Issa, S. Binish Zahra, M. Adnan Khan, and M. Kamrul Hasan, "Alzheimer disease detection empowered with transfer learning," Computers, Materials \& Continua, vol. 70, no. 3, pp. 5005-5019, Oct. 2021.

[61]. N. Ali, T. M. Ghazal, A. Ahmed, S. Abbas, M. A. Khan, H. M. Alzoubi, U. Farooq, M. Ahmad, and M. Adnan Khan, "Fusion-based supply chain collaboration using Machine Learning Techniques," Intelligent Automation \& Soft Computing, vol. 31, no. 3, pp. 16711687, Oct. 2021.

[62]. M. K. Hasan, T. M. Ghazal, A. Alkhalifah, K. A. Abu Bakar, A. Omidvar, N. S. Nafi, and J. I. Agbinya, "Fischer linear discrimination and quadratic discrimination analysisbased data mining technique for internet of things framework for Healthcare," Frontiers in Public Health, vol. 9, Oct. 2021.

[63]. R. Bibi, Y. Saeed, A. Zeb, T. M. Ghazal, T. Rahman, R. A. Said, S. Abbas, M. Ahmad, and M. A. Khan, "Edge AI-based automated detection and classification of road anomalies in VANET using Deep Learning," Computational Intelligence and Neuroscience, vol. 2021, pp. 1-19, Sep. 2021.

[64]. M. Adnan Khan, T. M. Ghazal, S.-W. Lee, and A. Rehman, "Data Fusion-based machine learning architecture for intrusion detection," Computers, Materials \& Continua, vol. 70, no. 2, pp. 3399-3413, Sep. 2021.

[65]. T. M. Ghazal, S. Noreen, R. A. Said, M. Adnan Khan, S. Yamin Siddiqui, S. Abbas, S. Aftab, and M. Ahmad, "Energy demand forecasting using fused machine learning approaches," Intelligent Automation \& Soft Computing, vol. 31, no. 1, pp. 539-553, Sep. 2021.

[66]. T. M. Ghazal, "Internet of things with Artificial Intelligence for Health Care Security," Arabian Journal for Science and Engineering, Aug. 2021. 
[67]. T. M. Ghazal, M. K. Hasan, M. T. Alshurideh, H. M. Alzoubi, M. Ahmad, S. S. Akbar, B. Al Kurdi, and I. A. Akour, "IOT for Smart Cities: Machine Learning Approaches in smart healthcare-A Review," Future Internet, vol. 13, no. 8, p. 218, Aug. 2021.

[68]. Mehmood, T., Alzoubi, H, Alshurideh, M., Al-Gasaymeh, A., \&Ahmed, G. (2019). Schumpeterian Entrepreneurship Theory: Evolution and Relevance. Academy of Entrepreneurship Journal, 25(4). 1-10, doi.org/10.1080/13662716.2016.1216397

[69]. Alzoubi, H., Ahmed, G., Al-Gasaymeh, A., \& Alkurdi, B. (2019). Empirical study on Sustainable Supply Chain Strategies and its impact on Competitive Priorities: The mediating role of Supply Chain Collaboration. Management Science Letters, 10(3), 703708, doi.org/10.5267/j.msl.2019.9.008

[70]. Alzoubi, H. \& Ahmed, G. (2019). Do Total Quality Management (TQM) Practices Improve Organisational Success? A case study of electronics industry in the UAE. International Journal of Economics and Business Research, 17(4), 459-472, doi.org/10.1504/IJEBR.2019.099975

[71]. Al-Gasaymeh, A., Ahmed, G., Mehmood, T. \& Alzoubi, H. (2019). Co-Integration Tests and the Long-Run Purchasing Power Parity: A Case Study of India and Pakistan Currencies. Theoretical Economics Letters, 9(4), 570-583.

[72]. Alzoubi, H., Abdo M., Al-Gasaymeh, A. \& Alzoubi, A. (2019). An empirical study of e-Service quality and its impact on achieving a value added. Journal of Business and Retail Management Research (JBRMR), 13(4), 138-145.

[73]. Alzoubi, H. (2018). The Role of Intelligent Information System in e-Supply Chain Management Performance. International Journal of Multidisciplinary Thought, 7(2), 363370.

[74]. Alzoubi, A., Al-Gasaymeh, A., \& Alzoubi, H. (2018). The Impact of Changes in the Qualitative Characteristics of Accounting Information on the Quality of Investment Decisions: A Field Study in the Brokerage Offices. The Journal of Economic and Management Perspectives (JEMP), 12(4), 67-82.

[75]. Alnazer, N., Alnuaimi, M. \& Alzoubi, H. (2017). Analyzing the Appropriate Cognitive Styles and its effect on Strategic Innovation in Jordanian Universities. International journal of business excellence, 13(1), 127-140, doi.org/10.1504/IJBEX.2017.085799

[76]. Khafajy, N., Alzoubi, H. \& Aljanabee, A. (2016). Analyzing the effect of knowledge management processes in the services' quality in Iraqi commercial banks. International Review of Management and Business Research, 5(1), 302-314. 
[77]. Alzoubi, H., Alnazer, N. \& Alzoubi, A. (2016). Exploring the Impact of the use of Business Information systems BIS on the organizational performance effectiveness. International Journal of Business and Management Invention, 5(4), 48-55.

[78]. Alnuaimi, M., Alzoubi, H., Alzubi, A. \& AL-Shinewi, M. (2015). The Impact of Managers Efficiency on Quality of Strategic Decision-making under Crisis Management. European Journal of Business and Management, 7(26), 156-166.

[79]. Alrubaiee, L., Alzubi, H., Hanandeh, R. \& Ali, R. (2015). Investigating the Relationship between Knowledge Management Processes and Organizational Performance: The Mediating Effect of Organizational Innovation. International Review of Management and Business Research, 4(4), 977-997

[80]. Alzoubi, H. \& Khafajy, N. (2015). The Impact of Business Process Management on Business Performance Superiority. International Journal of Business and Management Review, 3(2), 17-34

[81]. Alzubi, H., Mohammad, S. \& Abu-salma, A. (2015). Evaluating Strategic Quality Management Dimensions Using Analytic Hierarchy Process (AHP) and its Impact on Organizational Success. International Journal of Research in Management, 5(1), 137-150.

[82]. Mohammad, S., Abu-salma, A. \& Alzoubi, H. (2015). American Muslims' Perceptions Toward Transforming Islamic Banking System. International Journal of Economics, Commerce and Management, 5(1), 1-16.

[83]. Alrubaiee, L., Al zuobi, H. \& Abu-Alwafa, R. (2013). Exploring the Relationship between Quality Orientation, New Services Development and Organizational Performance. American Academic \& Scholarly Research Journal, 5(3), 315-329.

[84]. Alzoubi, H. \& Khafajy, N. (2010). Analyze the Impact of Managers Awareness of Environmental Uncertainty on Exploiting Strategic Competencies. Egyptian Journal for Commercial Studies, 34(2), 611-625.

[85]. Al-zu'bi, H. (2010). Applying Electronic Supply Chain Management Using MultiAgent System: A Managerial Perspective. International Arab Journal of e-Technology, 1(3), 106-113.

[86]. Alnuaimi, M., Alzoubi, A. \& Alzoubi, H. (2010). Propose a model for Performance Criteria and measuring its impact for Achieving Excellence. Association of Arab Universities Journal, 56(4), 920-941. 